\title{
The new world order
}

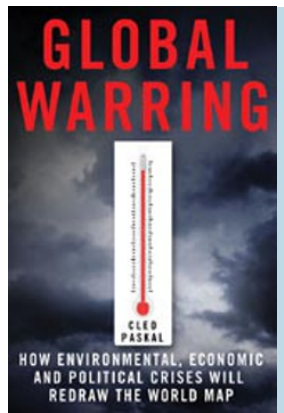

\section{GLOBAL WARRING: HOW ENVIRONMENTAL, ECONOMIC, AND POLITICAL CRISES WILL REDRAW THE WORLD MAP}

\author{
by Cleo Paskal \\ Palgrave Macmillan: 2010. 280pp. £20
}

\section{The United States and European Union will face off against China and Russia as climate change starts to alter the geopolitical gameboard.}

Cleo Paskal must be cursing the publishing gods. All anyone wants to talk about these days is purloined emails, errors in the reports of the Intergovernmental Panel on Climate Change, and the literary pursuits of its chair Rajendra Pachauri. Had Paskal's first book, Global Warring: How Environmental, Economic, and Political Crises will Redraw the World Map, come out last fall, she'd have timed it perfectly.

Consider this series of events: in September, the US Central Intelligence Agency (CIA) opened a centre on climate change and national security at its Virginian headquarters. That same month, the United Kingdom's newly appointed climate and security envoy embarked on a global tour, talking up the threats posed by rising seas, glacial melt, worsening droughts and other warming-related impacts. In November, international senior security experts warned that climate change could become a 'threat multiplier' in volatile regions. Overnight, it seemed, the term 'climate security' had become a buzzword in foreign policy circles.

Having followed these developments, I assumed that Paskal's book would simply sketch out the hellish scenarios of climate mayhem the CIA is now entrusted with anticipating. So I was surprised to see Paskal, a London-based journalist and a scholar at the think tank Chatham House, instead present a fascinating geopolitical chessboard, on which the United States and the European Union face off against China and Russia as climate change takes hold. If Western policymakers want to see how this game is playing out, they ought to read this book.

\section{PRIZED PASSAGE}

Paskal convincingly argues that shortsighted domestic and foreign policies are already eroding "the West's position in the global balance of power". Exhibit A is the Arctic, where the US and EU are pushing for 'global governance' of the still-frozen Northwest Passage, a route expected to become a prized shipping channel to Asia and Europe with continued warming.

Canada currently claims the Northwest Passage as part of its

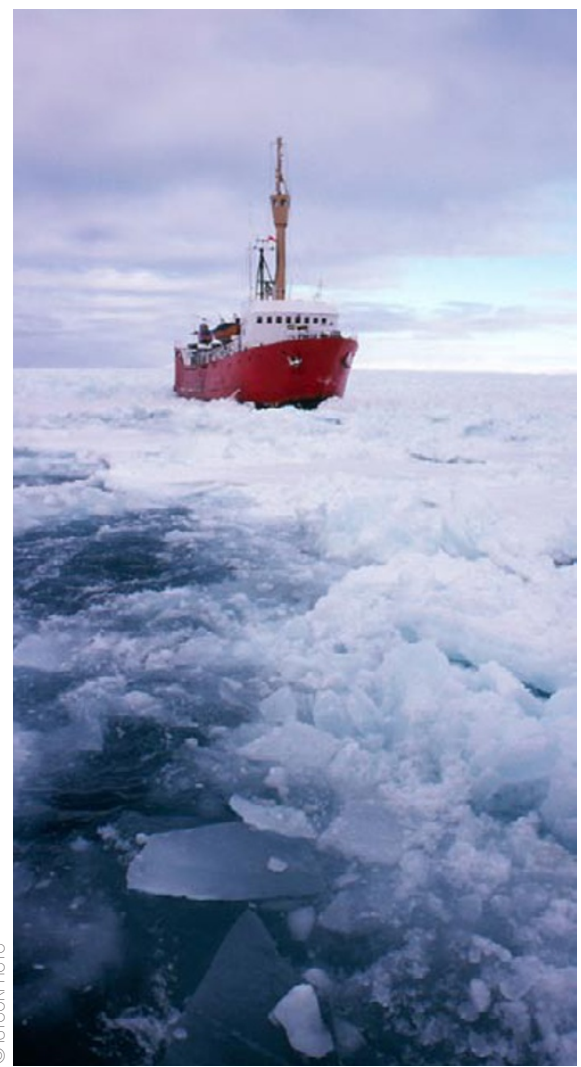

As melting Arctic sea ice opens a shipping channel through the Northwest Passage, China and Russia could forge economic ties to Canada and win major gains in trade. territorial waters, but this assertion is being contested by the US and European Union, which want it recognized as an international strait so that they can have unfettered access for their own commercial interests, such as oil and gas exploration. This standoff, Paskal suggests, could prod Canada to explore a strategic relationship with Russia, which has its own designs on the Arctic. Meanwhile, China is knocking at Canada's door, eager to purchase a slice of the country's abundant natural resources. In a 'stateless' Northwest Passage, Russia and China could end up being the big players, especially if they forge stronger economic ties to Canada. This potential development, Paskal argues, poses a longterm security risk to the EU and US.

To understand why the Northwest Passage looms large in global geopolitics, one need only look to China, which has built up a trading and shipping network through state-controlled companies that now manage such chokepoints as the Panama Canal. As Paskal explains, these chokepoints, where a wide flow of traffic is forced through a narrow alley, "are the sorts of things empires go to war over". The Strait of Hormuz, which leads to the oil fields of the Persian Gulf, is a natural chokepoint. Others, such as the Panama Canal, are man-made. "The melting Arctic sea ice creates new chokepoints of global strategic importance," asserts Paskal, cautioning those who minimize the Northwest Passage as a Canadian issue, "It is about as much of a Canadian issue as the Suez Canal is simply an Egyptian issue."

\section{CHINESE CHESS}

The melding of realpolitik and international relations with climate change is what makes Global Warring deserving of attention. 
Paskal spends much of the book walking the reader through the projected impacts of climate change - but in the context of countries manoeuvring for advantage in a world where imminent and drastic environmental change is taken for granted.

Take the example of the low-lying islands in the Pacific threatened by rising seas: here China is throwing its economic weight around to gain access to natural resources and critical trade routes. This shrewd positioning, combined with China's financial deal-making in Africa and Asia, is cementing strategic alliances that have greatly expanded China's sphere of influence. In just about every corner of the world, Paskal sees the United States being outflanked by China, mainly because China's economic interests are integrated with its foreign policy - what Paskal refers to as 'nationalistic capitalism'. Market economies, by contrast, seek to maximize private profit, not to advance the state's agenda.
On the domestic front, Paskal criticizes the US and China in equal measure on their planning for climate change. Although Hurricane Katrina - rightly or wrongly - provided a megaphone for advocates of mitigating climate change, to Paskal the 2005 disaster served notice on how ill-prepared the United States is for the impacts ahead. And everything the US has done since, such as continuing with coastal development and subsidizing flood insurance, has proven that Americans are not taking climate change seriously. China faces even more daunting environmental challenges, given its breakneck development and pollution problems, yet it shares the same blind spots at the US.

It is unfortunate that Paskal's highly readable and perceptive book is marred by structural problems that keep the whole from cohering. For example, at the end of one chapter the reader is tantalized by a glimpse of decisions "that may dangerously undermine North American and European security". But the next chapter begins with a tour of the Arctic permafrost by a local nature guide and is followed by chapters covering China's strategic use of nationalistic capitalism and Russia's re-emergence as a global power before Paskal returns, some 50 pages later, to some of those decisions that are undermining Western security.

But that shouldn't put readers off mining this very important book. It would be welcome, after all, if we could turn the public discussion back to the projected impacts of climate change and how they threaten to remake the global political order.

doi:10.1038/climate.2010.18

Published online: 25 February 2010

Keith Kloor

Keith Kloor is a freelance writer based in Brooklyn, New York.

e-mail:kkloor@msn.com

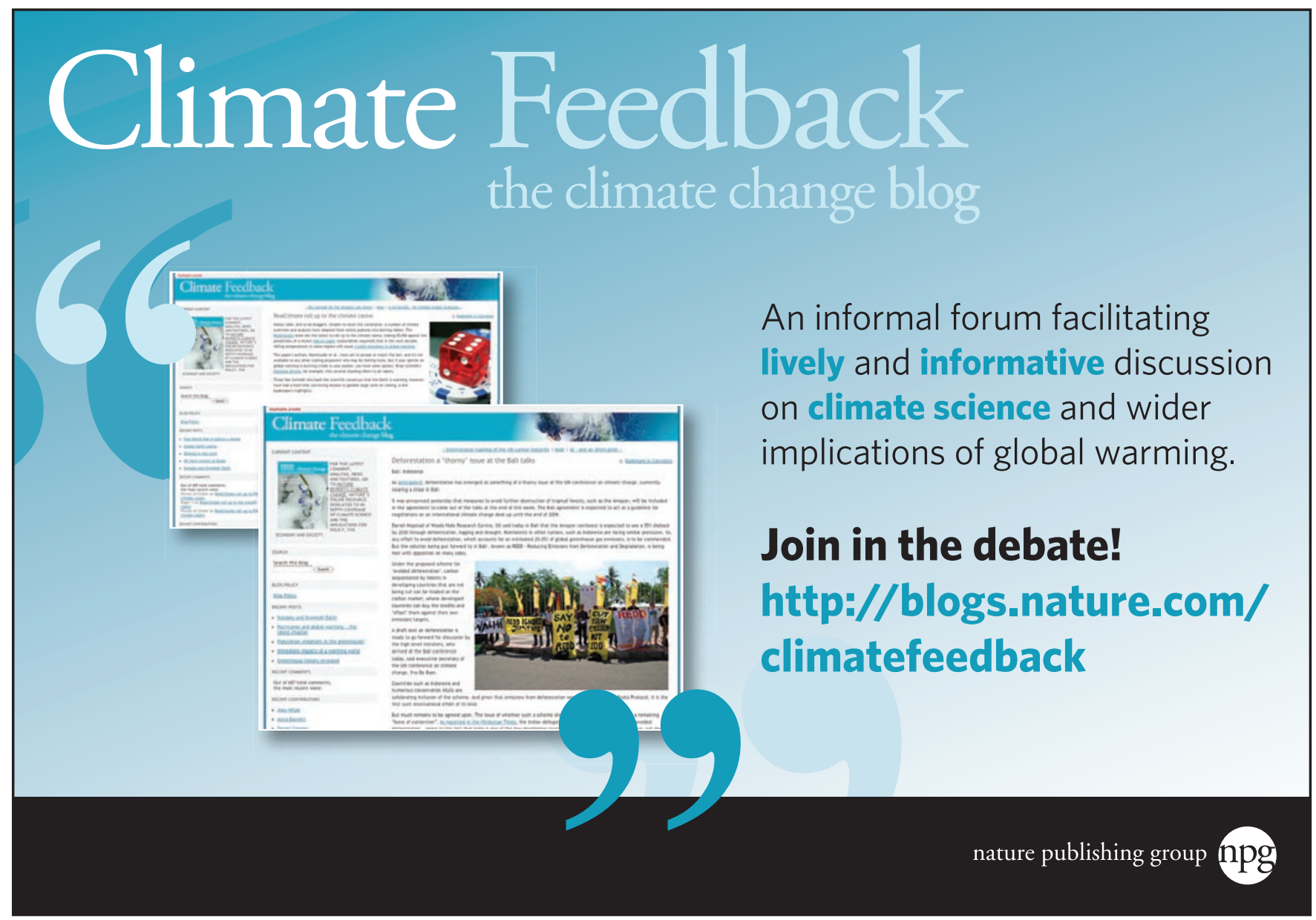

